\title{
Co-fermentation of
} Propionibacterium freudenreichii and Lactobacillus brevis in Wheat Bran for in situ Production of Vitamin B12

\author{
Chong Xie*, Rossana Coda, Bhawani Chamlagain, Pekka Varmanen, Vieno Piironen and \\ Kati Katina
}

Department of Food and Nutrition, University of Helsinki, Helsinki, Finland

\section{OPEN ACCESS}

Edited by:

Baltasar Mayo,

Spanish National Research Council (CSIC), Spain

Reviewed by:

Pasquale Russo,

University of Foggia, Italy

Anna Reale,

Institute of Food Sciences, National

Research Council (CNR-ISA), Italy

Stéphanie Deutsch,

INRA - Centre Bretagne Normandie,

France

*Correspondence:

Chong Xie

chong.xie@helsinki.fi

Specialty section:

This article was submitted to

Food Microbiology,

a section of the journa

Frontiers in Microbiology

Received: 26 February 2019 Accepted: 20 June 2019

Published: 05 July 2019

Citation:

Xie C, Coda R, Chamlagain B, Varmanen $P$, Piironen $V$ and Katina $K$

(2019) Co-fermentation of Propionibacterium freudenreichii and Lactobacillus brevis in Wheat

Bran for in situ Production of Vitamin B12. Front. Microbiol. 10:1541. doi: 10.3389/fmicb.2019.01541
The present study investigated the effect of co-fermentation on vitamin B12 content and microbiological composition of wheat bran. Propionibacterium freudenreichii DSM 20271 was used as the producer of vitamin while Lactobacillus brevis ATCC 14869 was selected to ensure the microbial safety of the bran dough. Fermentation trials were conducted in bioreactors to monitor and adjust the $\mathrm{pH}$ of the ferments. Vitamin B12 level reached $357 \pm 8 \mathrm{ng} / \mathrm{g}$ dry weight ( $\mathrm{dw}$ ) after 1 day of $\mathrm{pH}$-controlled fermentation with $P$. freudenreichii monoculture and remained stable thereafter. In co-fermentation with $L$. brevis, slightly less vitamin B12 (255 $\pm 31 \mathrm{ng} / \mathrm{g} \mathrm{dw}$ ) was produced in 1 day and an effective inhibition of the growth of total Enterobacteriaceae and Bacillus cereus was obtained. On day 3, vitamin B12 content in $\mathrm{pH}$-controlled co-fermentation increased to $332 \pm 44 \mathrm{ng} / \mathrm{g} \mathrm{dw}$. On the other hand, without a pH control, co-fermentation resulted in a stronger inhibition of Enterobacteriaceae and B. cereus but a lower level of vitamin B12 (183 $\pm 5 \mathrm{ng} / \mathrm{g} d \mathrm{w}$ on day 3 ). These results demonstrated that wheat bran fermented by $P$. freudenreichii and $L$. brevis can be a promising way to produce vitamin $B 12$ fortified plant-origin food ingredients, which could reduce cereal waste streams and contribute to a more resilient food chain.

Keywords: Propionibacterium freudenreichii, Lactobacillus brevis, bioreactor, vitamin B12, wheat bran, co-fermentation

\section{INTRODUCTION}

Vitamin B12 plays an important role in human body and its deficiency may result in megaloblastic anemia, peripheral arterial diseases and various neurological disorders (Nielsen et al., 2012; Zsori et al., 2013). Previously, deficiency of this vitamin was considered as rare, but recent studies found that varying degrees of suboptimal vitamin B12 status, ranging from insufficiency to outright deficiency, have wide prevalence and affect people of all ages (Green et al., 2017; Smith et al., 2018). Considering animal products are the main dietary source of vitamin B12, developing plantorigin food products fortified with vitamin B12 is a promising way to increase dietary vitamin B12 intake of people consuming limited amounts of animal products (Watanabe et al., 2014). Among 
the plant-based food matrices, cereal and cereal bran are the most abundant in the world and are an excellent material for innovative food applications. As the by-product of wheat (Triticum aestivum) milling process, a huge quantity of wheat bran is produced every year and yet most of it is discarded or used for feed due to its poor technological performance (Coda et al., 2015). Propionibacterium freudenreichii is a generally recognized as safe (GRAS) bacterium with the ability to produce active vitamin B12 in different plant-based matrices (Chamlagain et al., 2017; Signorini et al., 2018; Wolkers-Rooijackers et al., 2018). In our previous work, we demonstrated the possibility of producing physiologically significant amount of active vitamin B12 in nonsterile wheat bran using fermentation with $P$. freudenreichii (Xie et al., 2018). However, growth of potential pathogens, such as enterobacteria, from endogenous microbiota during wheat bran fermentation may result in safety concerns of the fermented dough to be used in food applications (Xie et al., 2018).

Co-fermentation with lactic acid bacteria (LAB) could be a feasible solution to improve the microbiological safety of the fermented bran matrix. LAB are a group of bacteria widely used in cereal fermentation to improve the flavor, nutrient contents and texture of products (De Vuyst and Neysens, 2005). Moreover, LAB can also produce various natural antimicrobials, contributing to the safety of fermented food products (Leroy and De Vuyst, 2004; Axel et al., 2017; Leyva Salas et al., 2017). Cultivation of propionibacteria (PAB) with LAB in cheese production is a typical example of commensalism because lactic acid produced by $\mathrm{LAB}$ is the preferential carbon source for PAB (Smid and Lacroix, 2013). Co-cultivation of PAB and $\mathrm{LAB}$ is also an appropriate choice for industrial biopreservation due to their production of various antimicrobial compounds (Smid and Lacroix, 2013). In addition, a co-fermentation process of LAB-PAB has been shown to produce vitamin B12 and folate in sterilized whey permeate medium (Hugenschmidt et al., 2011). However, producing vitamin B12 during the cofermentation of LAB-PAB in non-sterile wheat bran matrices has not yet been reported.

There is only a limited number of studies on co-fermentation of LAB-PAB in cereal-based products, and most of them are focused on the preservative effect of these cultures. For instance, a mixed culture pre-fermentation of LAB and PAB can improve the shelf-life of wheat or rye sourdough breads as a result of the acid production (Javanainen and Linko, 1993a,b). Tinzl-Malang et al. (2015) also reported the antifungal, texture-building and anti-staling ability of LAB-PAB co-fermentation in wheat bread due to the synergistic effects of exopolysaccharide and acid productions. Notably, pH control was used in all above mentioned studies, most probably to avoid inhibition of PAB growth and metabolism by rapid $\mathrm{pH}$ drop caused by acid producing LAB (Chaia et al., 1994).

The aim of this study was to investigate the production of vitamin B12 by $P$. freudenreichii DSM 20271 in wheat bran during its co-fermentation with Lactobacillus brevis ATCC 14869 with or without a $\mathrm{pH}$ control. The strain of $L$. brevis was chosen based on a pre-screening study to improve the microbial safety of the fermented bran. The acidification properties, microbial growth, sugar metabolism and the change in riboflavin (a precursor for synthesis of vitamin B12) content were also monitored to follow the microbial metabolism during the co-fermentation.

\section{MATERIALS AND METHODS}

\section{Pre-screening of Culture Combinations}

To select a suitable culture in co-fermentation with $P$. freudenreichii for improving the microbial safety of fermented bran, Saccharomyces cerevisiae $\mathrm{H} 10$ and 7 strains of LAB belonging to the species: Lactobacillus reuteri, Leuconostoc pseudomesenteroides, Lactobacillus delbrueckii, Weissella confusa, Leuconostoc mesenteroides, and L. brevis (strain codes and origins in Supplementary Table S1), previously used for cereal or bran fermentation, were separately used for co-fermentation with $P$. freudenreichii DSM 20271. Wheat bran doughs (400 g) were prepared by mixing $80 \mathrm{~g}$ bran with $320 \mathrm{~g}$ water. After transferring into $500 \mathrm{ml}$ bottles, doughs were inoculated at the initial cell density of $9.0 \mathrm{log}$ colony forming units (CFU)/g of $P$. freudenreichii and $6.0 \log \mathrm{CFU} / \mathrm{g}$ of LAB or yeast. The initial inoculum level of $P$. freudenreichii was performed according to our previous study to produce sufficient content of vitamin B12 (Xie et al., 2018). The inoculum levels of LAB or yeast were determined by preliminary experiments to achieve a significant inhibition on Enterobacteriaceae growth with a minor inhibition on production of vitamin B12. Doughs were fermented in shaking conditions $(200 \mathrm{rpm})$ for 3 days at $25^{\circ} \mathrm{C}$ and during fermentation, $\mathrm{pH}$ value was measured every $12 \mathrm{~h}$. When the value dropped below 5.5, $\mathrm{pH}$ was adjusted to 6.0 with $3 \mathrm{M} \mathrm{NaOH}$ (no adjustment at $60 \mathrm{~h}$ ). The fermentations were carried out in biological duplicate. After day 0,1 , and 3 , samples of $20 \mathrm{~g}$ were taken out for cell count measurement of $\mathrm{PAB}$ and total Enterobacteriaceae. Based on the acidification properties (Supplementary Table S2) and the inhibitory effect on the propagation of Enterobacteriaceae (Supplementary Table S3), L. brevis ATCC 14869 was selected for further co-fermentation experiments.

\section{Raw Material, Microbial Strains, and Culture Preparation}

The milled wheat bran was obtained from Fazer Mills (Lahti, Finland). More than $99 \%$ of bran particles are smaller than $790 \mu \mathrm{m}$ and about $80 \%$ of them were larger than $224 \mu \mathrm{m}$. The composition of the bran was $16.0 \%$ protein, $20.0 \%$ available carbohydrate, $43.0 \%$ fiber, $4.8 \%$ lipids, $12.5 \%$ moisture, and 3.9\% ash, as provided by the manufacturer.

Both $P$. freudenreichii and $L$. brevis cultures were cryopreserved at $-60^{\circ} \mathrm{C}$ in glycerol. $P$. freudenreichii was propagated in the yeast extract lactate (YEL) medium (Malik et al., 1968) at $30^{\circ} \mathrm{C}$ for 3 days and L. brevis was propagated in de Man, Rogosa and Sharpe (MRS) medium (Lab M, Lancashire, United Kingdom) at $37^{\circ} \mathrm{C}$ for 1 day. After incubation, the cultures were recovered by centrifugation $(3,200 \times \mathrm{g}, 10 \mathrm{~min})$ and resuspended in MillQ water before inoculation. 
TABLE 1 | PH and $\mathrm{NaOH}$ consumption (ml) during controlled fermentation.

\begin{tabular}{|c|c|c|c|c|c|c|}
\hline Sample code & Starter* & Initial pH & Final $\mathrm{pH}$ & Time $(\mathbf{h})^{* *}$ & $\begin{array}{l}\text { NaOH consumption (5 M) } \\
\text { after } 1 \text { day }\end{array}$ & $\begin{array}{c}\mathrm{NaOH} \text { consumption (5 M) } \\
\text { after } 3 \text { day }\end{array}$ \\
\hline Control & - & 6.5 & 5.0 & 19 & $11 \pm 1^{a}$ & $32 \pm 2^{a}$ \\
\hline PF_C & $P . f$ & 6.5 & 5.0 & 20 & $14 \pm 1^{b}$ & $36 \pm 2^{a}$ \\
\hline CO_C & P. $f+L . b$ & 6.5 & 5.0 & 11 & $24 \pm 4^{c}$ & $43 \pm 1^{b}$ \\
\hline CO_U & P. $f+$ L. $b$ & 6.5 & 3.7 & 11 & - & - \\
\hline
\end{tabular}

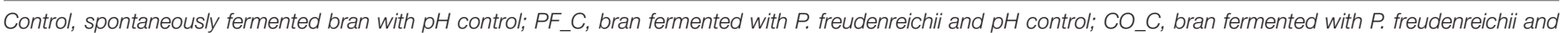

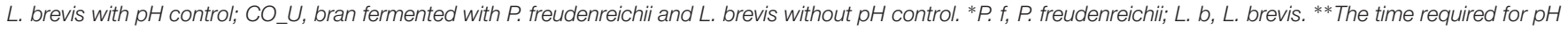
decreasing to 5.0. Values bearing different superscripts $(a-c)$ in the same column are significantly different $(p<0.05)$.

\section{Fermentation}

Four different wheat bran doughs were fermented as outlined in Table 1: spontaneously fermented bran dough with $\mathrm{pH}$ control (Control); bran dough fermented with $P$. freudenreichii monoculture with $\mathrm{pH}$ control (PF_C); bran dough fermented with $P$. freudenreichii/L. brevis co-culture with $\mathrm{pH}$ control (CO_C); bran dough fermented with $P$. freudenreichii/L. brevis co-culture without $\mathrm{pH}$ control (CO_U). In each fermentation, $1 \mathrm{~kg}$ of wheat bran dough was prepared by mixing bran and water in a 15:85 ratio. Wheat bran doughs were transferred in three bioreactors (Sartorius, Goettingen, Germany) and successively inoculated with the microbial starters. Fermentation was carried out for $72 \mathrm{~h}$ at $25^{\circ} \mathrm{C}$, with stirring set at $600 \mathrm{rpm}$. In doughs fermented with $\mathrm{pH}$ control, $5 \mathrm{M} \mathrm{NaOH}$ solution was used to maintain the $\mathrm{pH}$ value at 5.0.

Propionibacterium freudenreichii was inoculated at the initial cell density of $9.0 \log$ colony forming units (CFU)/g and L. brevis at the level of $6.0 \log$ CFU/g. At time 0, 24, and $72 \mathrm{~h}$, samples of $80 \mathrm{~g}$ were taken. An aliquot of $10 \mathrm{~g}$ was used for the cell count determinations and the rest of the samples were stored $\left(-20^{\circ} \mathrm{C}\right)$ for other analyses. Three biological replicate fermentations were carried out for each dough type.

\section{Microbial Counts}

To estimate the number of viable cells, bran doughs $(10 \mathrm{~g})$ were serially diluted in sterile saline solution $(8.5 \mathrm{~g} / \mathrm{L}$ of $\mathrm{NaCl})$ and appropriate dilutions were plated on the agar plates. YEL plates were incubated anaerobically for 4 days in anaerobic jars with Anaerogen (Oxoid, Basingstoke, United Kingdom) followed by 1 day incubation under aerobic conditions at $30^{\circ} \mathrm{C}$. In these conditions, the colonies of $P$. freudenreichii turn brownish to be distinguishable from colonies of other bacteria. MRS agar (Lab M) for the cell counts of LAB was supplemented with $0.01 \%$ of cycloheximide (Sigma Chemical Co., United States) and microaerobically incubated at $30^{\circ} \mathrm{C}$ for $48 \mathrm{~h}$. Plate count agar (PCA) plates (Lab M) were used for the cell counts of total aerobic bacteria. Yeast and mould (YM) agar plates $(3 \mathrm{~g} / \mathrm{L}$ malt extract, $3 \mathrm{~g} / \mathrm{L}$ yeast extract, $5 \mathrm{~g} / \mathrm{L}$ peptone, $10 \mathrm{~g} / \mathrm{L}$ dextrose, and $0.01 \%$ chloramphenicol) were used for the cell counts of yeast. Total Enterobacteriaceae were enumerated on the violet red bile glucose agar (VRBGA) plates (Lab M). Polymyxin egg yolk mannitol bromothymol blue agar (PEMBA) plates (Lab M) were used for the cell counts of Bacillus cereus. PCA, YM, and PEMBA plates were incubated aerobically at $30^{\circ} \mathrm{C}$ for $48 \mathrm{~h}$, VRBGA plates were incubated aerobically at $37^{\circ} \mathrm{C}$ for $48 \mathrm{~h}$.

\section{Determination of Acids}

Lactic acid, acetic acid and propionic acid were determined using a high-performance liquid chromatography (HPLC) method. Dough samples $(1 \mathrm{~g})$ after dilution $(1: 10, \mathrm{w} / \mathrm{v})$ in MilliQ water were centrifuged $(3,200 \times \mathrm{g}, 10 \mathrm{~min})$ and supernatants were filtered $(0.45 \mu \mathrm{m}$, Pall, United States) before injection. HPLC analysis was performed with the same instrument and the method as reported in the earlier study (Xie et al., 2018).

\section{Determination of Monosaccharides}

Arabinose, galactose, xylose, glucose, and fructose were analyzed by high performance anion exchange chromatography equipped with a pulse amperometric detection system (HPAEC-PAD). Before analysis, dough samples diluted in water $(1: 10, \mathrm{w} / \mathrm{v})$ were filtered by an Amicon Ultra-0.5 centrifugal filter unit (Millipore, Billerica, MA, United States) at $12,000 \times \mathrm{g}$ for $10 \mathrm{~min}$ to get rid of polymeric molecules. Monosaccharides were separated on a CarboPac PA1 column $(250 \times 4 \mathrm{~mm}$ i.d., Dionex, Sunnyvale, CA, United States) and detected using a Waters 2465 pulsed amperometric detector (Waters, United States). The solvents used were $200 \mathrm{mM} \mathrm{NaOH}$ and MilliQ water. A gradient elution was maintained at a constant flow rate of $1 \mathrm{ml} / \mathrm{min}$ : 0-31 min, $2 \mathrm{mM} \mathrm{NaOH}$; 31-33 min, $200 \mathrm{mM} \mathrm{NaOH}$; and 33$50 \mathrm{~min}, 2 \mathrm{mM} \mathrm{NaOH}$, with an additional $10 \mathrm{~min}$ washing and regeneration steps. The injection volume was $10 \mu l$. Glucose (Merck, Germany), fructose (Merck), xylose (Merck), arabinose (Merck), and galactose (Merck) were used as external standards and 2-deoxy-D-galactose (Sigma-Aldrich, Germany) was used as the internal standard for quantification.

\section{Determination of Vitamin B12}

Vitamin B12 in the bran dough was extracted in cyano form and determined by an Ultra-HPLC (UHPLC) method as described by Xie et al. (2018). During determination, the presence of other corrinoids, especially pseudovitamin B12, was followed in the chromatograms based on their retention times and absorption spectra according to our previous studies (Chamlagain et al., 2015, 2017; Deptula et al., 2015).

Briefly, dough samples $(3 \mathrm{~g})$ were mixed with $15 \mathrm{ml}$ of extraction buffer $(8.3 \mathrm{mM}$ sodium hydroxide and $20.7 \mathrm{mM}$ acetic acid, $\mathrm{pH} 4.5)$ and $100 \mu \mathrm{l}$ of sodium cyanide ( $1 \% \mathrm{w} / \mathrm{v}$ in water). 
After extraction in boiling water $(30 \mathrm{~min})$, cooled mixtures were incubated in a water bath $\left(30 \mathrm{~min}, 37^{\circ} \mathrm{C}\right)$ with addition of $300 \mu \mathrm{l} \alpha$-amylase $(50 \mathrm{mg} / \mathrm{ml}$; St Louis, MO, United States) to allow the breakdown of starch before centrifugation $(6,900 \times g$, $10 \mathrm{~min})$. Residues after centrifugation were suspended in $5 \mathrm{ml}$ of extraction buffer and centrifuged again. Both supernatants were combined and adjusted to the same volume $(25 \mathrm{ml})$ with the extraction buffer. Finally, $10 \mathrm{ml}$ of the extracts were purified using an immunoaffinity column (Easi-Extract; R-Biopharm; Glasgow, Scotland) and analyzed with a Waters UPLC system (Milford, MA, United States) as explained by Chamlagain et al. (2015).

\section{Determination of Riboflavin}

Content of riboflavin in doughs was determined with a UHPLC method according to Chamlagain et al. (2016) with minor modification. Samples $(2 \mathrm{~g})$ were mixed with $15 \mathrm{ml}$ of $0.1 \mathrm{M}$ hydrochloric acid and extracted in a boiling water bath (60 min). After cooling on ice, the $\mathrm{pH}$ of the mixture was adjusted to 4.5 with $2.5 \mathrm{M}$ sodium acetate and incubated at $37^{\circ} \mathrm{C}$ with Taka-Diastase (50 mg; Pfaltz and Bauer, CT, United States) and $\beta$-amylase ( $5 \mathrm{mg}$; Sigma-Aldrich) for $24 \mathrm{~h}$. The extract was filtered (0.2 $\mu \mathrm{m}$, Pall, United States) and analyzed on a Waters UPLC system with an Acquity BEH C18 column $(2.1 \times 100 \mathrm{~mm}$, $1.7 \mu \mathrm{m})$ and a Waters fluorescence detector using aqueous methanol (30\% v/v) containing $20 \mathrm{mM}$ ammonium acetate as an eluent $(0.2 \mathrm{ml} / \mathrm{min})$.

\section{Statistical Analysis}

Statistical analysis was performed using SPSS 24.0 for Windows (IBM Corporation, NY, United States). One-way analysis of variance (ANOVA) and Tukey's post hoc test were used to determine significant differences at a $p$-value $<0.05$ among the samples.

\section{RESULTS}

\section{Pre-screening of Co-fermentation Cultures}

Supplementary Tables $\mathbf{S 2}-\mathbf{S} 4$ show the change in $\mathrm{pH}$ values and the cell counts of total Enterobacteriaceae and PAB during bran dough fermentation with $P$. freudenreichii monoculture and in co-fermentation of $P$. freudenreichii with $\mathrm{LAB} /$ yeast strains. In general, dough $\mathrm{pH}$ dropped more rapidly and lower cell densities of Enterobacteriaceae were counted in doughs co-fermented with LAB compared to doughs co-fermented with yeast or fermented with P. freudenreichii monoculture. Fastest drop in $\mathrm{pH}$ and the lowest cell counts of Enterobacteriaceae on both day $1(2.4 \pm 0.2$ $\log \mathrm{CFU} / \mathrm{g})$ and day $3(3.2 \pm 0.2 \log \mathrm{CFU} / \mathrm{g})$ were observed in fermentations including $L$. brevis as a starter. The cell density of $P$. freudenreichii in all combinations varied from 8.9 to $9.4 \mathrm{log}$ $\mathrm{CFU} / \mathrm{g}$ during fermentation.

\section{Microbial Counts of Bran Doughs}

In the control dough, no $\mathrm{PAB}$ were detected throughout the fermentation (Table 2). The initial cell density of $P$. freudenreichii was ca. $8.7 \log \mathrm{CFU} / \mathrm{g}$ on day 0 due to the inoculum. In the PF_C and CO_C doughs, cell density of P. freudenreichii increased from ca. $8.7 \log \mathrm{CFU} / \mathrm{g}$ to ca. 9.2 log CFU/g during the first day and remained stable thereafter. In the CO_U dough, the cell density of $P$. freudenreichii remained constant from day 0 to day 3 .

In doughs without L. brevis inoculation (control and PF_C), the initial cell density of LAB was ca. 3.0 log CFU/g and increased to ca. $9.8 \log \mathrm{CFU} / \mathrm{g}$ on day 1 . In the CO_C and CO_U doughs, the initial cell densities of LAB were ca. $6.3 \mathrm{log} \mathrm{CFU} / \mathrm{g}$ and increased to ca. 10.2 log CFU/g and ca. 9.6 log CFU/g on day 1 , respectively. From day 1 to day 3 , cell density of LAB remained stable in the CO_C dough but decreased of $0.5 \mathrm{log}$ units in the CO_U dough. The initial cell densities of the total aerobic

TABLE 2 | Cell counts (log CFU/g) of Propionibacteria (PAB), lactic acid bacteria $(\llcorner\mathrm{AB})$, total aerobic bacteria, yeasts, total Enterobacteriaceae, and Bacillus cereus during bran dough fermentation.

\begin{tabular}{|c|c|c|c|}
\hline Time (days) & 0 & 1 & 3 \\
\hline \multicolumn{4}{|l|}{ PAB } \\
\hline Control & nd* & nd & nd \\
\hline PF_C & $8.8 \pm 0.1^{a, x}$ & $9.2 \pm 0.1^{b, y}$ & $9.0 \pm 0.1^{b, y}$ \\
\hline CO_C & $8.7 \pm 0.1^{a, x}$ & $9.1 \pm 0.1^{b, y}$ & $8.9 \pm 0.2^{b, x y}$ \\
\hline CO_U & $8.6 \pm 0.1^{a, x}$ & $8.6 \pm 0.2^{a, x}$ & $8.5 \pm 0.1^{a, x}$ \\
\hline \multicolumn{4}{|l|}{ LAB } \\
\hline Control & $2.7 \pm 0.3^{a, x}$ & $9.8 \pm 0.2^{a, y}$ & $9.8 \pm 0.2^{a, y}$ \\
\hline PF_C & $3.0 \pm 0.2^{a, x}$ & $9.7 \pm 0.2^{a, y}$ & $9.6 \pm 0.1^{a, y}$ \\
\hline CO_C & $6.3 \pm 0.2^{b, x}$ & $10.2 \pm 0.0^{b, y}$ & $10.3 \pm 0.2^{b, y}$ \\
\hline CO_U & $6.4 \pm 0.2^{b, x}$ & $9.6 \pm 0.2^{a, z}$ & $9.1 \pm 0.1^{a, y}$ \\
\hline \multicolumn{4}{|c|}{ Total aerobic bacteria } \\
\hline Control & $5.2 \pm 0.2^{a, x}$ & $9.8 \pm 0.4^{a, y}$ & $9.8 \pm 0.1^{b, y}$ \\
\hline PF_C & $5.2 \pm 0.0^{a, x}$ & $9.6 \pm 0.2^{a, y}$ & $9.6 \pm 0.2^{b, y}$ \\
\hline $\mathrm{CO} C \mathrm{C}$ & $6.4 \pm 0.3^{b, x}$ & $9.9 \pm 0.3^{a, y}$ & $10.2 \pm 0.2^{c, y}$ \\
\hline $\mathrm{CO} \cup \mathrm{U}$ & $6.5 \pm 0.2^{b, x}$ & $9.7 \pm 0.2^{a, z}$ & $9.2 \pm 0.2^{a, y}$ \\
\hline \multicolumn{4}{|l|}{ Yeasts } \\
\hline Control & $3.7 \pm 0.3^{a, x}$ & $5.1 \pm 0.0^{b, y}$ & $5.4 \pm 0.1^{b, y}$ \\
\hline PF_C & $3.7 \pm 0.1^{a, x}$ & $5.1 \pm 0.2^{b, y}$ & $5.3 \pm 0.1^{b, y}$ \\
\hline CO_C & $3.6 \pm 0.2^{a, x}$ & $3.6 \pm 0.2^{a, x}$ & $5.1 \pm 0.3^{b, y}$ \\
\hline $\mathrm{CO} \mathrm{U}$ & $3.6 \pm 0.1^{a, x}$ & $3.4 \pm 0.2^{a, x}$ & $3.6 \pm 0.2^{a, x}$ \\
\hline \multicolumn{4}{|c|}{ Total Enterobacteriaceae } \\
\hline Control & $4.8 \pm 0.0^{a, y}$ & $6.1 \pm 0.1^{b, z}$ & $3.7 \pm 0.3^{b, x}$ \\
\hline PF_C & $4.7 \pm 0.1^{a, y}$ & $6.0 \pm 0.1^{\mathrm{b}, \mathrm{z}}$ & $3.7 \pm 0.1^{b, x}$ \\
\hline CO_C & $4.7 \pm 0.1^{a, y}$ & $3.3 \pm 0.3^{a, x}$ & $3.4 \pm 0.4^{b, x}$ \\
\hline CO_U & $4.8 \pm 0.1^{a, z}$ & $3.4 \pm 0.3^{a, y}$ & $2.8 \pm 0.1^{a, x}$ \\
\hline \multicolumn{4}{|c|}{ Bacillus cereus } \\
\hline Control & $3.2 \pm 0.1^{\mathrm{a}, \mathrm{x}}$ & $3.1 \pm 0.0^{b, x}$ & nd \\
\hline PF_C & $3.3 \pm 0.0^{a, x}$ & $3.4 \pm 0.1^{b, x}$ & nd \\
\hline CO_C & $3.2 \pm 0.2^{a, y}$ & $2.4 \pm 0.1^{\mathrm{a}, \mathrm{x}}$ & nd \\
\hline CO_U & $3.1 \pm 0.1^{\mathrm{a}}$ & nd & nd \\
\hline
\end{tabular}

*nd, not detected. Control, spontaneously fermented bran with $\mathrm{pH}$ control; PF_C, bran fermented with P. freudenreichii and $\mathrm{pH}$ control; CO_C, bran fermented with P. freudenreichii and $L$. brevis with $\mathrm{pH}$ control; CO_U, bran fermented with $P$. freudenreichii and $L$. brevis without $\mathrm{pH}$ control. The results are expressed as the mean \pm standard deviation $(n=3)$. Values from the same day and microbial group bearing different superscripts $(a-c)$ are significantly different $(p<0.05)$. Values from the same dough type and microbial group bearing different superscripts $(x-z)$ are significantly different $(p<0.05)$. 
bacteria ranged from ca. $5.2 \log \mathrm{CFU} / \mathrm{g}$ to $6.4 \mathrm{log} \mathrm{CFU} / \mathrm{g}$. During fermentation, their cell densities increased in the range of ca. 9.2 $\log \mathrm{CFU} / g$ to $10.2 \log \mathrm{CFU} / \mathrm{g}$.

The initial cell density of yeasts was approximately $3.7 \mathrm{log}$ CFU/g on day 0 . The cell density of yeasts increased to ca. 5.1 $\log$ CFU/g on day 1 in doughs without L. brevis inoculation but remained unaltered afterward in co-fermented doughs. On day 3 , yeast cell number in the CO_U dough was significantly $(p<0.05)$ lower than in the other doughs.

Before fermentation, ca. $4.8 \log \mathrm{CFU} / \mathrm{g}$ of total Enterobacteriaceae and ca. $3.2 \mathrm{log} \mathrm{CFU} / \mathrm{g}$ of $\mathrm{B}$. cereus were found in wheat bran dough. In the control and PF_C doughs, cell densities of Enterobacteriaceae increased to ca. $6.0 \mathrm{log} \mathrm{CFU} / \mathrm{g}$ on day 1 and decreased to ca $3.7 \log \mathrm{CFU} / \mathrm{g}$ on day 3 . In the CO_C dough, cell density of total Enterobacteriaceae was ca. 3.3 $\log \mathrm{CFU} / \mathrm{g}$ on day 3. In the CO_U dough, the final cell density of Enterobacteriaceae ( $2.8 \pm 0.1 \log \mathrm{CFU} / \mathrm{g})$ was significantly $(p<0.05)$ lower than in the other doughs. B. cereus was not detected in the CO_U dough but a cell density of 2.4 to $3.0 \mathrm{log}$ $\mathrm{CFU} / \mathrm{g}$ of $B$. cereus was still detected in the other 3 doughs after 1 day of fermentation. However, on day 3, B. cereus was not found in any of the four doughs.

\section{Acidification of the Doughs}

On day 0 , the $\mathrm{pH}$ value of all the doughs were ca. 6.5 (Table 1). In the doughs inoculated with $P$. freudenreichii/L. brevis co-culture $\mathrm{pH}$ dropped most rapidly and reached $\mathrm{pH} 5.0$ already after $11 \mathrm{~h}$. In the dough inoculated with $P$. freudenreichii monoculture and in the control dough, $\mathrm{pH}$ dropped similarly and reached $\mathrm{pH} 5.0$ after 20 and $19 \mathrm{~h}$, respectively. At the end of fermentation, $\mathrm{pH}$ 3.7 was reached in the CO_U dough while in other doughs $\mathrm{pH}$ remained at 5.0.

Among the doughs with $\mathrm{pH}$ control, the highest consumption of $\mathrm{NaOH}$ solution $(5 \mathrm{M})$ was found in the $\mathrm{CO}$-C dough both on day $1(24 \pm 4 \mathrm{ml})$ and day $3(43 \pm 1 \mathrm{ml})$. The consumption of $\mathrm{NaOH}$ in the PF_C dough $(14 \pm 1 \mathrm{ml})$ was significantly $(p<0.05)$ higher than in the control dough $(11 \pm 1 \mathrm{ml})$ on day 1 but there was no significant $(p>0.05)$ difference in $\mathrm{NaOH}$ consumption between these two doughs on day 3 .

Before fermentation, lactic, acetic and propionic acid were not detected in any of the doughs (Figure 1). On day 1, the concentration of lactic acid in the CO_C dough was $204 \pm 14 \mathrm{mg} / \mathrm{g}$ dry weight (dw), which was significantly $(p<0.05)$ higher than in the other doughs (ranging from ca. 79 to $96 \mathrm{mg} / \mathrm{g} \mathrm{dw}$ ). On day 3, lactic acid content in the doughs with a $\mathrm{pH}$ control had no significant $(p>0.05)$ difference and varied from 212 to $250 \mathrm{mg} / \mathrm{g} \mathrm{dw}$. In the CO_U dough, the concentration of lactic acid was $98 \pm 2 \mathrm{mg} / \mathrm{g} \mathrm{dw}$ at day 3 .

On day 1, the highest amount of acetic acid was found in the PF_C dough $(20.3 \pm 1.0 \mathrm{mg} / \mathrm{g} \mathrm{dw})$. Concentration of acetic acid in the control dough $(12.8 \pm 3.5 \mathrm{mg} / \mathrm{g} \mathrm{dw})$ was significantly $(p<0.05)$ higher than in the CO_C $(3.6 \pm 0.6 \mathrm{mg} / \mathrm{g} \mathrm{dw})$ and the CO_U dough $(1.8 \pm 0.1 \mathrm{mg} / \mathrm{g} \mathrm{dw})$. On day 3 , the highest concentration of acetic acid was found in the PF_C dough $(40.3 \pm 1.6 \mathrm{mg} / \mathrm{g} \mathrm{dw})$ and the lowest concentration was found in the CO_U dough $(3.1 \pm 0.6 \mathrm{mg} / \mathrm{g} \mathrm{dw})$.
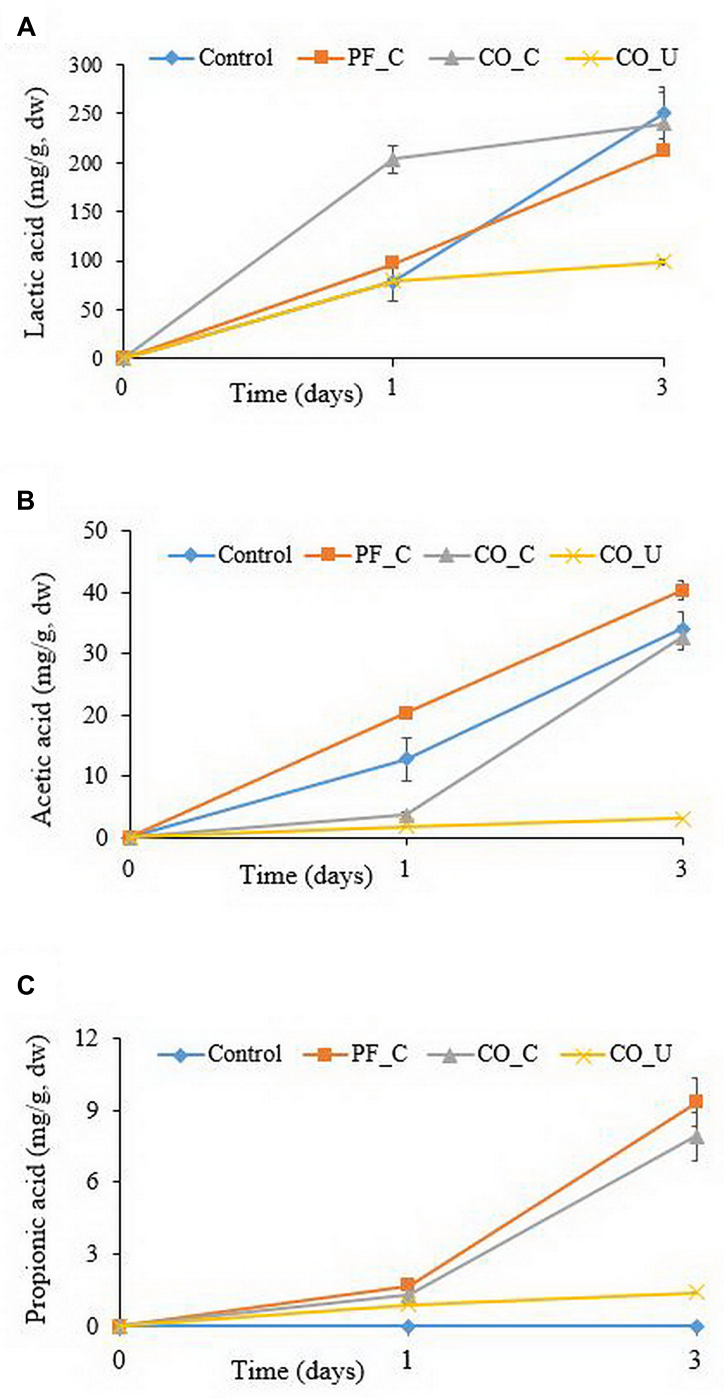

FIGURE 1 | Concentration (mg/g, dry weight) of lactic acid (A), acetic acid (B), and propionic acid (C) during fermentation. Values are means and standard deviations of three replicates. Control, spontaneously fermented bran with $\mathrm{pH}$ control; PF_C, bran fermented with $P$. freudenreichii monoculture and $\mathrm{pH}$ control; CO_C, bran fermented with P. freudenreichii/L. brevis co-culture with $\mathrm{pH}$ control; $\mathrm{CO} \_U$, bran fermented with $P$. freudenreichii/ $L$. brevis co-culture without $\mathrm{pH}$ control.

Propionic acid was not detected in the control dough throughout the fermentation. In other doughs, the level of propionic acid ranged from 0.9 to $1.7 \mathrm{mg} / \mathrm{g} \mathrm{dw}$ on day 1 . On day 3 , the CO_U dough had the lowest concentration of propionic acid $(1.4 \pm 0.1 \mathrm{mg} / \mathrm{g} \mathrm{dw})$ and the level of propionic acid in the other two doughs had no significant $(p>0.05)$ difference and ranged from 7.9 to $9.3 \mathrm{mg} / \mathrm{g} \mathrm{dw}$.

\section{Monosaccharides in Bran Doughs}

On day 0 , the main monosaccharides in wheat bran doughs were glucose $(3.4 \mathrm{mg} / \mathrm{g} \mathrm{dw})$ and fructose $(2.3 \mathrm{mg} / \mathrm{g} \mathrm{dw})$ while 


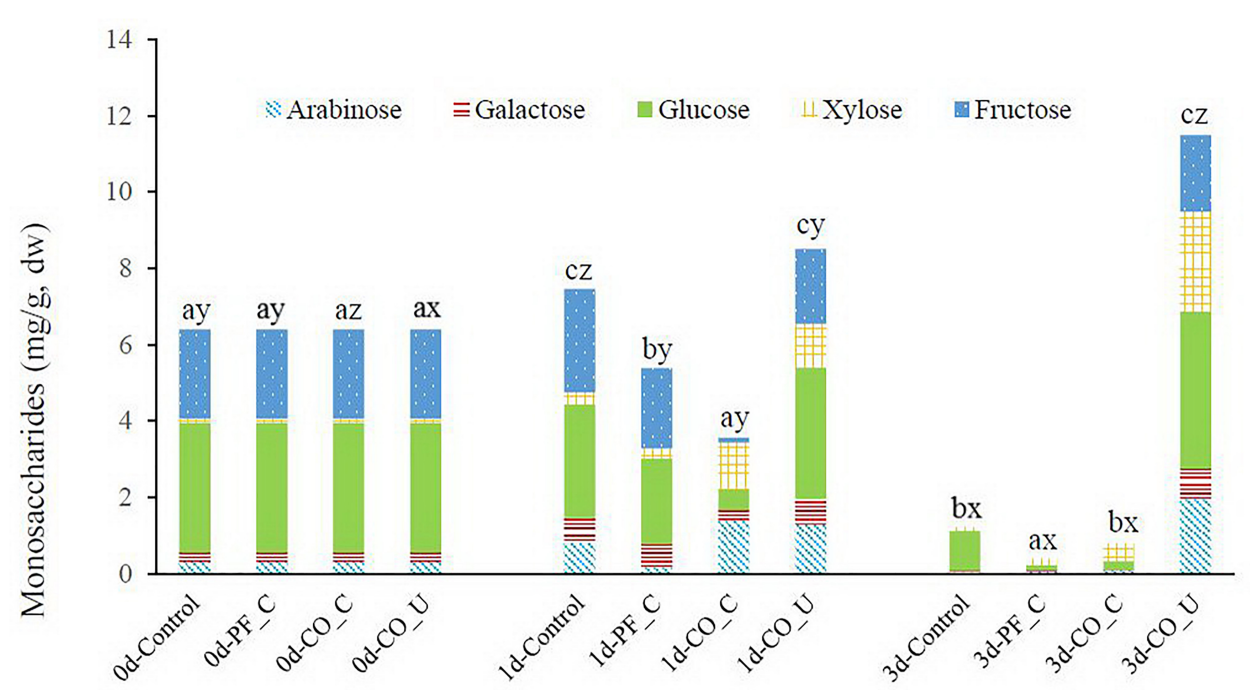

Time (days) and dough types

FIGURE 2 | Concentration (mg/g, dry weight) of arabinose, galactose, glucose, xylose, and fructose during fermentation. Values are means and standard deviations of three replicates. Control, spontaneously fermented bran with pH control; PF_C, bran fermented with P. freudenreichii monoculture and pH control; CO_C, bran fermented with $P$. freudenreichii/L. brevis co-culture with $\mathrm{pH}$ control; $\mathrm{CO} \_\mathrm{U}$, bran fermented with $P$. freudenreichii/L. brevis co-culture without pH control. Values of total monosaccharide concentration from the same day bearing different superscripts $(a-c)$ are significantly different $(p<0.05)$. Values of total monosaccharide concentration from the same dough type bearing different superscripts $(x-z)$ are significantly different $(p<0.05)$.

xylose, galactose and arabinose were present at levels ranging from 0.1 to $0.3 \mathrm{mg} / \mathrm{g} \mathrm{dw}$ (Figure 2). In the control dough, concentration of galactose, xylose and arabinose increased during the first day and the sum of monosaccharides increased from ca. $6.4 \mathrm{mg} / \mathrm{g} \mathrm{dw}$ to ca. $7.5 \mathrm{mg} / \mathrm{g} \mathrm{dw}$. However, only ca. $1.2 \mathrm{mg} / \mathrm{g}$ $\mathrm{dw}$ of monosaccharides was detected in the control dough on day 3. Content of monosaccharides in the PF_C dough was ca. $5.4 \mathrm{mg} / \mathrm{g} \mathrm{dw}$ and was mainly composed by glucose and fructose on day 1, while in the CO_C dough there was ca. $3.6 \mathrm{mg} / \mathrm{g} \mathrm{dw}$ of monosaccharides on day 1, mostly composed of xylose and arabinose. On day 3, there were ca. $0.4 \mathrm{mg} / \mathrm{g} \mathrm{dw}$ and ca. $0.8 \mathrm{mg} / \mathrm{g}$ $\mathrm{dw}$ of monosaccharides in the PF_C dough and the CO_C dough, respectively. In the $\mathrm{CO}$ _U dough, the concentration of all monosaccharides, except fructose, increased from day 0 to day 3 and reached a sum of ca. $11.5 \mathrm{mg} / \mathrm{g} \mathrm{dw}$ at the end of fermentation.

\section{Vitamin B12 in Bran Doughs}

In the control dough, no vitamin B12 was detected during fermentation (Figure 3). In other doughs, ca. $40 \mathrm{ng} / \mathrm{g} \mathrm{dw}$ of vitamin $\mathrm{B} 12$ were found on day 0 from the $P$. freudenreichii inoculum. On day 1, the highest content of vitamin B12 was found in the PF_C dough $(357 \pm 9 \mathrm{ng} / \mathrm{g} \mathrm{dw})$. In the CO_C dough and the CO_U dough, vitamin B12 concentration were $255 \pm 31$ and $214 \pm 35 \mathrm{ng} / \mathrm{g}$ dw on day 1 , respectively. From day 1 to day 3 , there was no significant $(p>0.05)$ increase of vitamin B12 concentration in the PF_C dough and the CO_U dough. In the CO_C dough, concentration of vitamin B12 increased to $332 \pm 34 \mathrm{ng} / \mathrm{g} \mathrm{dw}$ on day 3 , which was on the same level as in the PF_C dough.

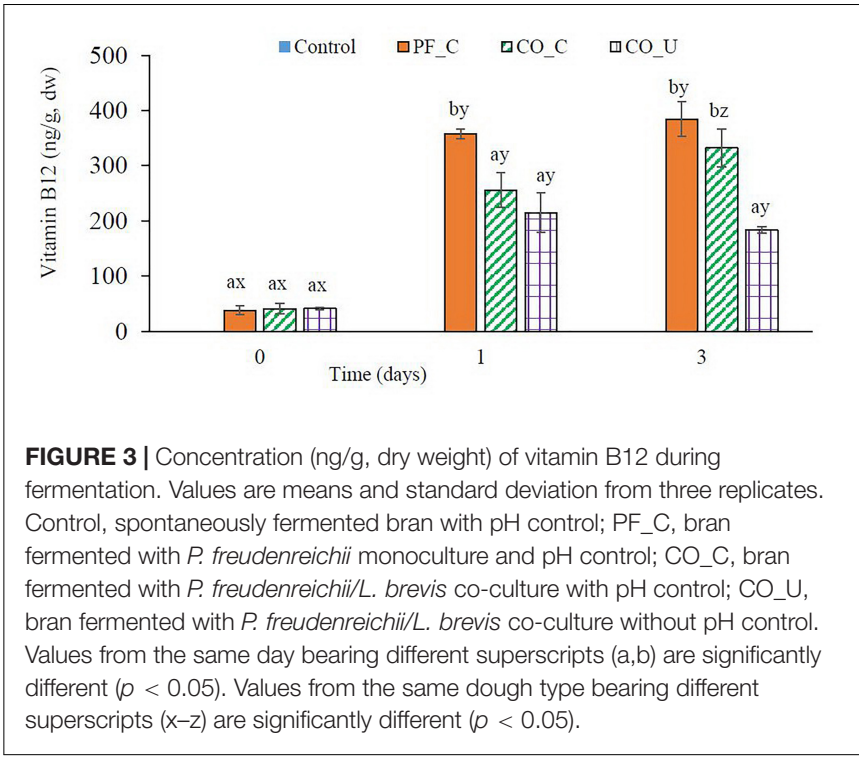

\section{Riboflavin in Bran Doughs}

Before fermentation, wheat bran doughs contained ca. $4.0 \mu \mathrm{g} / \mathrm{g}$ $\mathrm{dw}$ of riboflavin (Figure 4). In the control dough, concentration of riboflavin had no significant $(p>0.05)$ change during fermentation. In other doughs, riboflavin concentrations were significantly $(p<0.05)$ lower on day 1 varying from ca. $3.2 \mu \mathrm{g} / \mathrm{g}$ dw to ca. $3.5 \mu \mathrm{g} / \mathrm{g}$ dw. From day 1 to day 3, concentration of 


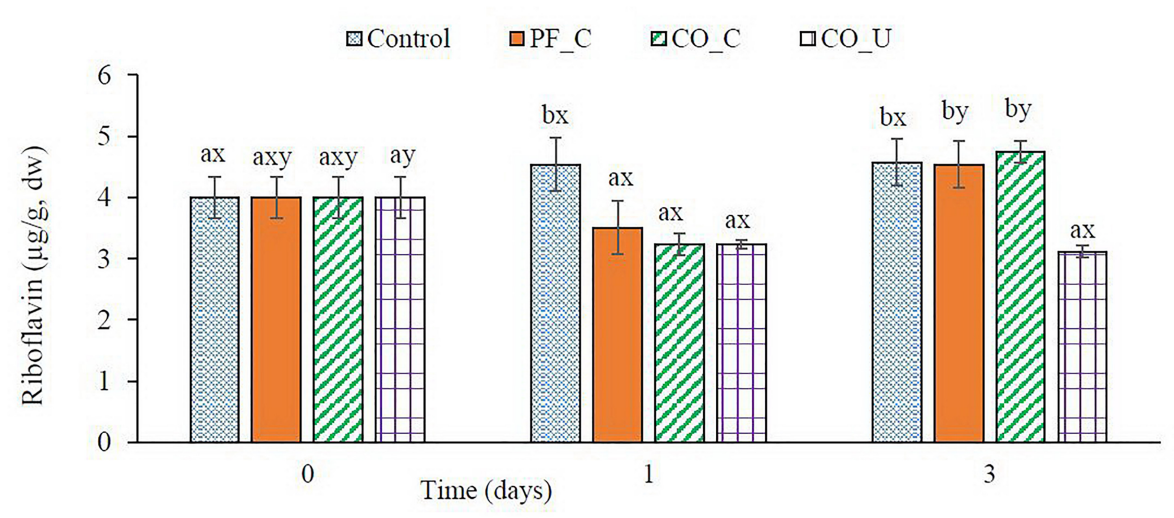

FIGURE 4 | Concentration ( $\mu \mathrm{g} / \mathrm{g}$, dry weight) of riboflavin during fermentation. Values are means and standard deviation from three replicates. Control, spontaneously fermented bran with $\mathrm{pH}$ control; PF_C, bran fermented with $P$. freudenreichii monoculture and pH control; $\mathrm{CO}$ _C, bran fermented with $P$. freudenreichii/L. brevis co-culture with $\mathrm{pH}$ control; $\mathrm{CO} \_U$, bran fermented with $P$. freudenreichii/L. brevis co-culture without pH control. Values from the same day bearing different superscripts $(a, b)$ are significantly different $(p<0.05)$. Values from the same dough type bearing different superscripts $(x, y)$ are significantly different $(p<0.05)$.

riboflavin increased to ca. $4.6 \mu \mathrm{g} / \mathrm{g}$ dw in the PF_C dough and the $\mathrm{CO} \_\mathrm{C}$ dough while it remained stable in the $\mathrm{CO} \_\mathrm{U}$ dough.

\section{DISCUSSION}

In the present study, non-sterile wheat bran was used for in situ fortification of vitamin B12 by co-fermentation of P. freudenreichii DSM 20271 and L. brevis ATCC 14869 in controlled conditions. This strain of $P$. freudenreichii was found to be a promising vitamin B12 producer in our previous study (Xie et al., 2018). A pre-screening phase was conducted to select the best performing starter for co-fermentation with $P$. freudenreichii in wheat bran to reduce the growth of Enterobacteriaceae, and improve the microbial safety of fermented wheat bran. L. brevis ATCC 14869 was selected as it exhibited the strongest antagonistic activity. The adaptability and performance of different strains of L. brevis in bran has been shown previously, including the positive effect on the quality of bread containing fermented wheat bran (Coda et al., 2014; Valerio et al., 2014; Messia et al., 2016).

\section{Microbiological Characteristics of Fermentation}

The microbiota of the wheat bran doughs was composed of endogenous microorganisms and the added microbial inocula. In the doughs with starters, the cell density of $P$. freudenreichii was ca. $8.7 \log \mathrm{CFU} / \mathrm{g}$ before fermentation while the cell density of $\mathrm{LAB}$ was ca. $6.3 \log \mathrm{CFU} / \mathrm{g}$ in the doughs with addition of $L$. brevis and ca. $3.0 \mathrm{log} \mathrm{CFU} / \mathrm{g}$ in doughs without $L$. brevis inoculation. However, either endogenous or inoculated LAB outnumbered the cell density of $P$. freudenreichii and dominated fermentation already after 1 day of fermentation. Yeasts are a group of microorganisms commonly found in sourdough, co-existing with LAB and the LAB:yeast ratio has been shown to be generally 100:1 during traditional wheat sourdough fermentation (De Vuyst and Neysens, 2005). Similarly to our previous results (Xie et al., 2018), in the present study, LAB:yeast ratio in the control dough was about 10000:1 during fermentation. Meanwhile, addition of L. brevis inhibited the growth of yeasts on day 1 . However, the cell density of yeasts increased to ca. $5.3 \mathrm{log} \mathrm{CFU} / \mathrm{g}$ on day 3 in the CO_C dough but remained stable in the CO_U dough suggesting that inhibition of $L$. brevis on yeasts may be due to the decrease of $\mathrm{pH}$.

Native wheat bran also contained some undesirable potential pathogens, such as Enterobacteriaceae and B. cereus. Enterobacteriaceae is a large family of Gram negative bacteria and some members among this group are able to cause infections of the human gastrointestinal tract or might produce various endotoxins (Singh et al., 2015). B. cereus is a pathogenic foodborne species commonly existing in plant-origin products such as bread, rice and vegetables (Rosenquist et al., 2005). By producing heat-stable toxins in food, B. cereus can cause mild to severe nausea, vomiting and diarrheal illness in humans (Bottone, 2010). Therefore, controlling the growth of these bacteria during bran fermentation is very important for the safety of bran derived food.

Lactic acid bacteria can inhibit the growth of pathogens by production of acids and antimicrobial compounds as well as by competitive exclusion (Kostrzynska and Bachand, 2006). However, outgrowth of Enterobacteriaceae (ca. $6.0 \mathrm{log} \mathrm{CFU} / \mathrm{g}$ on day 1) in the control dough showed that spontaneous fermentation with endogenous LAB was not effective in controlling the cell propagation of Enterobacteriaceae. This may be due to the low initial level of endogenous LAB (ca. $3.0 \mathrm{log}$ $\mathrm{CFU} / \mathrm{g}$ ) and $\mathrm{pH}$ control condition during fermentation which may diminish the inhibitory effect of produced acids on potential pathogens. Inoculum with $P$. freudenreichii monoculture did not show inhibitory effect on Enterobacteriaceae growth either, and under the $\mathrm{pH}$ control conditions used here, only the additional starter culture provided a promising inhibition on Enterobacteriaceae.

The pre-screening revealed that all the LAB cultures tested could, to a varying extent, inhibit the growth of 
Enterobacteriaceae while L. brevis showed the strongest inhibition among them. During co-fermentation with L. brevis, the cell density of Enterobacteriaceae started to decrease on day 1 irrespective of whether $\mathrm{pH}$ was controlled or not. This inhibitory effect of $L$. brevis in the early stage can reduce the microbial risk e.g., potential production of endotoxins during fermentation and increase the overall quality of wheat bran. Moreover, the lower cell density of Enterobacteriaceae in CO_U dough $(2.8 \pm 0.1 \log \mathrm{CFU} / \mathrm{g})$ than in CO_C dough $(3.4 \pm 0.4 \mathrm{log}$ $\mathrm{CFU} / \mathrm{g}$ ) on day 3 showed that the lower $\mathrm{pH}$ (3.7 vs. 5.0) can enhance the inhibition of L. brevis on Enterobacteriaceae. Although in this study the dominance of $L$ brevis ATCC 14869 was not confirmed, the high level of inoculum (ca. 6.0 $\log \mathrm{CFU} / \mathrm{g}$ ) compared to the endogenous $\mathrm{LAB}$ of wheat bran (ca. $3.0 \log \mathrm{CFU} / \mathrm{g})$, and the significant $(p<0.05)$ difference of lactic acid (97 vs. $204 \mathrm{ug} / \mathrm{g} \mathrm{dw}$ ) and acetic acid (20 vs. $4 \mathrm{ug} / \mathrm{g} \mathrm{dw}$ ) content between the PF_C dough and CO_C dough suggest that the starter culture was able to steer the fermentation process.

\section{Utilization of Carbohydrates and Production of Acids}

Wheat bran contains various endogenous and microbial enzymes which can result in the release of various monosaccharides from complex carbohydrates during fermentation (Apprich et al., 2014; Immerzeel et al., 2014). Additionally, both inoculated and endogenous microorganisms in bran doughs also consumed monosaccharides to produce acids and other metabolites. In the control dough, endogenous LAB brought intensive acidification. However, from day 0 to day 1 , the level of monosaccharides in the control dough increased as a result of liberation of xylose and arabinose by hydrolysis of arabinoxylan, which comprises 10.9 to $26.0 \%$ of wheat bran (Onipe et al., 2015).

Propionibacterium freudenreichii prefers lactic acid as the carbon source during fermentation and produces propionic acid and acetic acid as the main metabolites (Lee et al., 1974). Addition of $P$. freudenreichii had no effect on the cell density of endogenous LAB but resulted in a faster utilization of monosaccharides and higher production of acids. When L. brevis ATCC 14869 was added (CO_C), higher level of lactic acid and lower level of acetic acid were found compared to the dough containing only $P$. freudenreichii (PF_C) and the spontaneously fermented dough on day 1. It was previously observed that co-fermentation of glucose and other carbon sources is a typical feature of L. brevis ATCC 14869 , in which a less rigorous hierarchical consumption of carbohydrates occurs. Additionally, simultaneous fermentation of glucose and fructose resulted in lactic acid and ethanol as the main products (Kim et al., 2009). After day 1, the level of acetic acid in the CO_C dough increased drastically, likely because of L. brevis ATCC 14869 started to use xylose and arabinose after fructose and glucose were almost depleted. In fact, the addition of $L$. brevis largely increased the hydrolysis of arabinoxylan during the first day of fermentation. From day 1 to day 3 , microorganisms in doughs with $\mathrm{pH}$ control still utilized monosaccharides and continued acid production. However, in the dough without $\mathrm{pH}$ control, no further acid production was observed after day 1 suggesting that the low $\mathrm{pH}$ reached might have inhibited the metabolic activity of the microorganisms. For example, PAB cannot produce acids when $\mathrm{pH}$ is lower than 4.5 (Piwowarek et al., 2018). On the other hand, contents of monosaccharides increased throughout the fermentation because some monosaccharide-releasing enzymes, such as xylanolytic enzymes, may still be active in this $\mathrm{pH}$ condition (Bajpai, 2014).

\section{Production of Vitamin B12}

The fact that vitamin B12 was not found in the control dough confirmed that vitamin B12 was only synthesized by the inoculated $P$. freudenreichii. In previous studies, the possibility to fortify plant-based substrates with vitamin B12 by $P$. freudenreichii fermentation was shown. For instance, it was found that $9 \mathrm{ng} / \mathrm{g}$ to $37 \mathrm{ng} / \mathrm{g}$ fresh weight (41 ng/g to $200 \mathrm{ng} / \mathrm{g}$ dry weight) of vitamin B12 were produced by fermentation of $P$. freudenreichii in autoclaved aqueous barley and wheat aleurone matrices (Chamlagain et al., 2017). Moreover, an increase of vitamin B12 content (up to $9.7 \mathrm{ng} / \mathrm{g}$ fresh weight) in lupin tempeh by co-fermentation of Rhizopus oryzae and $P$. freudenreichii was also reported (Wolkers-Rooijackers et al., 2018). In our former study, ca. $155 \mathrm{ng} / \mathrm{g} \mathrm{dw}$ of vitamin B12 was produced in wheat bran dough after a 7-day fermentation by $P$. freudenreichii with a final cell density at ca. $9.2 \mathrm{log} \mathrm{CFU} / \mathrm{g}$ (Xie et al., 2018). In the present study, ca. $200 \mathrm{ng} / \mathrm{g}$ dw of vitamin B12 was produced in the CO_U dough after only 1 day of fermentation by $P$. freudenreichii with a cell density at ca. $8.5 \mathrm{log} \mathrm{CFU} / \mathrm{g}$. Considering that cobalt is one of the limiting factors for vitamin B12 production by P. freudenreichii during fermentation (Hugenschmidt et al., 2011; Deptula et al., 2017; Xie et al., 2018), the higher production of vitamin B12 in the present study was probably due to the higher cobalt content in the wheat bran used here than in the one used in the previous study $(0.27$ vs. $0.1 \mu \mathrm{g} / \mathrm{g} \mathrm{dw}$; data not shown). In addition, according to Quesada-Chanto et al. (1994), the production of vitamin B12 by $P$. freudenreichii was strongly depending also on $\mathrm{pH}$ level. The optimal $\mathrm{pH}$ for the production was around 6.5. The higher concentration of vitamin B12 in the PF_C dough than in the CO_C dough on day 1 could be a result of slower acidification in PF_C dough. Moreover, from day 1 to day 3, the concentration of vitamin B12 increased continuously in the CO_C dough, which was not observed in the CO_U dough, implicating that $P$. freudenreichii was still able to produce vitamin $\mathrm{B} 12$ at $\mathrm{pH}$ 5.0. However, no further increase of vitamin B12 content was observed in the PF_C dough from day 1 to day 3 , possibly due to the depletion of available cobalt in the dough.

\section{Synthesizing Lower Ligand of Vitamin B12 From Riboflavin}

Since $P$. freudenreichii mainly produces the active form of vitamin B12 with a 5, 6-dimethylbenzimidazole (DMBI) as the lower ligand (Deptula et al., 2015) and no DMBI were added during fermentation, all the DMBI in the synthesized vitamin B12 
was from de novo biosynthesis. Riboflavin has been found to be the precursor for the de novo biosynthesis of DMBI in P. freudenreichii in the presence of oxygen (Hollriegl et al., 1982). After day 1, the content of riboflavin in doughs with vitamin B12 production was significantly $(p<0.05)$ lower than in the control dough confirming that $P$. freudenreichii synthesized DMBI from riboflavin. The content of riboflavin in the PF_C dough and the CO_C dough increased to the same level as in the control dough on day 3 because riboflavin can also be synthesized by $P$. freudenreichii and various LAB species commonly existing in wheat based sourdough microflora (Burgess et al., 2006; Capozzi et al., 2011; Russo et al., 2014).

\section{CONCLUSION}

This work demonstrated that $P$. freudenreichii can produce nutritionally relevant amount of vitamin B12 in wheat bran during co-fermentation with $L$. brevis and that the vitamin B12 production can be markedly enhanced by maintaining the medium $\mathrm{pH}$ above 5. Meanwhile, addition of L. brevis with $P$. freudenreichii can effectively inhibit the growth of total Enterobacteriaceae and $B$. cereus to ensure the safety of fermentation when $\mathrm{pH}$ was controlled around 5 . Therefore, wheat bran fermented with $P$. freudenreichii and $L$. brevis can be a promising alternative to produce vitamin B12 enriched ingredient for various food products. These applications could increase the use of wheat bran, thus

\section{REFERENCES}

Apprich, S., Tirpanalan, Ö., Hell, J., Reisinger, M., Böhmdorfer, S., SiebenhandlEhn, S., et al. (2014). Wheat bran-based biorefinery 2: valorization of products. LWT - Food Sci. Technol. 56, 222-231. doi: 10.1016/j.lwt.2013.12.003

Axel, C., Zannini, E., and Arendt, E. K. (2017). Mold spoilage of bread and its biopreservation: a review of current strategies for bread shelf life extension. Crit. Rev. Food Sci. Nutr. 57, 3528-3542. doi: 10.1080/10408398.2016.1147417

Bajpai, P. (2014). "Chapter 3 - microbial xylanolytic systems and their properties," in Xylanolytic Enzymes (Cambridge, MA: Academic Press), 19-36. doi: 10.1016/ b978-0-12-801020-4.00003-2

Bottone, E. J. (2010). Bacillus cereus, a volatile human pathogen. Clin. Microbiol. Rev. 23, 382-398. doi: 10.1128/CMR.00073-09

Burgess, C. M., Smid, E. J., Rutten, G., and Van Sinderen, D. (2006). A general method for selection of riboflavin-overproducing food grade micro-organisms. Microb. Cell Fact. 5:24.

Capozzi, V., Menga, V., Digesu, A. M., De Vita, P., Van Sinderen, D., Cattivelli, L., et al. (2011). Biotechnological production of vitamin B2-enriched bread and pasta. J. Agric. Food Chem. 59, 8013-8020. doi: 10.1021/jf201519h

Chaia, A. P., Strasser, D. E., Saad, A. M., De Ruiz Holgado, A. P., and Oliver, G. (1994). Competitive inhibition of propionibacterium acidipropionici by mixed culturing with Lactobacillus helveticus. J. Food Prot. 57, 341-344. doi: 10.4315/ 0362-028X-57.4.341

Chamlagain, B., Deptula, P., Edelmann, M., Kariluoto, S., Grattepanche, F., Lacroix, C., et al. (2016). Effect of the lower ligand precursors on vitamin B12 production by food-grade Propionibacteria. LWT Food Sci. Technol. 72, 117-124. doi: 10.1002/fsn3.528

Chamlagain, B., Edelmann, M., Kariluoto, S., Ollilainen, V., and Piironen, V. (2015). Ultra-high performance liquid chromatographic and mass spectrometric analysis of active vitamin B12 in cells of Propionibacterium and fermented cereal matrices. Food Chem. 166, 630-638. doi: 10.1016/j.foodchem. 2014.06.068 reducing cereal waste streams and contributing to a more resilient food chain.

\section{DATA AVAILABILITY}

The raw data supporting the conclusions of this manuscript will be made available by the authors, without undue reservation, to any qualified researcher.

\section{AUTHOR CONTRIBUTIONS}

CX performed the experiments and drafted the manuscript. $\mathrm{RC}, \mathrm{BC}, \mathrm{PV}, \mathrm{VP}$, and $\mathrm{KK}$ conceived the experiments and reviewed the manuscript.

\section{ACKNOWLEDGMENTS}

The authors acknowledge the China Scholarship Council for its financial support of this work.

\section{SUPPLEMENTARY MATERIAL}

The Supplementary Material for this article can be found online at: https://www.frontiersin.org/articles/10.3389/fmicb. 2019.01541/full\#supplementary-material

Chamlagain, B., Sugito, T., Deptula, P., Edelmann, M., Kariluoto, S., Varmanen, P., et al. (2017). In situ production of active vitamin B12 in cereal matrices using Propionibacterium freudenreichii. Food Sci. Nutr. 6, 67-76. doi: 10.1002/ fsn 3.528

Coda, R., Karki, I., Nordlund, E., Heinio, R. L., Poutanen, K., and Katina, K. (2014). Influence of particle size on bioprocess induced changes on technological functionality of wheat bran. Food Microbiol. 37, 69-77. doi: 10.1016/j.fm.2013. 05.011

Coda, R., Katina, K., and Rizzello, C. G. (2015). Bran bioprocessing for enhanced functional properties. Curr. Opin. Food Sci. 1, 50-55. doi: 10.1016/j.cofs.2014. 11.007

De Vuyst, L., and Neysens, P. (2005). The sourdough microflora: biodiversity and metabolic interactions. Trends Food Sci. Technol. 16, 43-56. doi: 10.1016/j.tifs. 2004.02.012

Deptula, P., Chamlagain, B., Edelmann, M., Sangsuwan, P., Nyman, T. A., Savijoki, K., et al. (2017). Food-like growth conditions support production of active vitamin b12 by Propionibacterium freudenreichii 2067 without dmbi, the lower ligand base, or cobalt supplementation. Front. Microbiol. 8:368. doi: 10.3389/ fmicb.2017.00368

Deptula, P., Kylli, P., Chamlagain, B., Holm, L., Kostiainen, R., Piironen, V., et al. (2015). BluB/CobT2 fusion enzyme activity reveals mechanisms responsible for production of active form of vitamin B12 by Propionibacterium freudenreichii. Microb. Cell Fact. 14:186. doi: 10.1186/s12934-0150363-9

Green, R., Allen, L. H., Bjorke-Monsen, A. L., Brito, A., Gueant, J. L., Miller, J. W., et al. (2017). Vitamin B12 deficiency. Nat. Rev. Dis. Primers 3:17040. doi: $10.1038 /$ nrdp. 2017.40

Hollriegl, V., Lamm, L., Rowold, J., Hörig, J., and Renz, P. (1982). Biosynthesis of vitamin B12. Different pathways in some aerobic and anaerobic microorganisms. Arch. Microbiol. 132, 155-158.

Hugenschmidt, S., Schwenninger, S. M., and Lacroix, C. (2011). Concurrent high production of natural folate and vitamin B12 using a co-culture process with 
Lactobacillus plantarum SM39 and Propionibacterium freudenreichii DF13. Process Biochem. 46, 1063-1070. doi: 10.1016/j.procbio.2011.01.021

Immerzeel, P., Falck, P., Galbe, M., Adlercreutz, P., Nordberg Karlsson, E., and Ståalbrand, H. (2014). Extraction of water-soluble xylan from wheat bran and utilization of enzymatically produced xylooligosaccharides by Lactobacillus, Bifidobacterium and Weissella spp. LWT - Food Sci. Technol. 56, 321-327. doi: 10.1016/j.lwt.2013.12.013

Javanainen, P., and Linko, Y. Y. (1993a). Factors affecting rye sour dough fermentation with mixed-culture pre-ferment of lactic and propionic acid bacteria. J . Cereal Sci. 18, 171-185. doi: 10.1006/jcrs.1993.1044

Javanainen, P., and Linko, Y. Y. (1993b). Utilization of sprout-damaged wheat as raw material for sour dough pre-ferments with mixed cultures of lactic and propionic acid bacteria. Food Biotechnol. 7, 99-113. doi: 10.1080/ 08905439309549850

Kim, J. H., Shoemaker, S. P., and Mills, D. A. (2009). Relaxed control of sugar utilization in Lactobacillus brevis. Microbiology 155, 1351-1359. doi: 10.1099/ mic. $0.024653-0$

Kostrzynska, M., and Bachand, A. (2006). Use of microbial antagonism to reduce pathogen levels on produce and meat products: a review. Can. J. Microbiol. 52, 1017-1026. doi: 10.1139/w06-058

Lee, I. H., Fredrick, A. G., and Tsuchiya, H. M. (1974). Diauxic growth of propionibacterium-shermanii. Appl. Microbiol. 28, 831-835.

Leroy, F., and De Vuyst, L. (2004). Lactic acid bacteria as functional starter cultures for the food fermentation industry. Trends Food Sci. Technol. 15, 67-78. doi: 10.1016/j.tifs.2003.09.004

Leyva Salas, M., Mounier, J., Valence, F., Coton, M., Thierry, A., and Coton, E. (2017). Antifungal microbial agents for food biopreservation-a review. Microorganisms 5:E37. doi: 10.3390/microorganisms5030037

Malik, A. C., Reinbold, G. W., and Vedamuthu, E. R. (1968). An evaluation of taxonomy of propionibacterium. Can. J. Microbiol. 14, 1185-1191. doi: $10.1139 / \mathrm{m} 68-199$

Messia, M. C., Reale, A., Maiuro, L., Candigliota, T., Sorrentino, E., and Marconi, E. (2016). Effects of pre-fermented wheat bran on dough and bread characteristics. J. Cereal Sci. 69, 138-144. doi: 10.1016/j.jcs.2016.03.004

Nielsen, M. J., Rasmussen, M. R., Andersen, C. B., Nexo, E., and Moestrup, S. K. (2012). Vitamin B12 transport from food to the body's cells-a sophisticated, multistep pathway. Nat. Rev. Gastroenterol. Hepatol. 9, 345-354. doi: 10.1038/ nrgastro.2012.76

Onipe, O. O., Jideani, A. I. O., and Beswa, D. (2015). Composition and functionality of wheat bran and its application in some cereal food products. Int. J. Food Sci Technol. 50, 2509-2518. doi: 10.1111/ijfs. 12935

Piwowarek, K., Lipinska, E., Hac-Szymanczuk, E., Kieliszek, M., and Scibisz, I. (2018). Propionibacterium spp.-source of propionic acid, vitamin B12, and other metabolites important for the industry. Appl. Microbiol. Biotechnol. 102, 515-538. doi: 10.1007/s00253-017-8616-7

Quesada-Chanto, A., Afschar, A., and Wagner, F. (1994). Optimization of a Propionibacterium acidipropionici continuous culture utilizing sucrose. Appl. Microbiol. Biotechnol. 42, 16-21. doi: 10.1007/s002530050209

Rosenquist, H., Smidt, L., Andersen, S. R., Jensen, G. B., and Wilcks, A. (2005). Occurrence and significance of Bacillus cereus and Bacillus thuringiensis in ready-to-eat food. FEMS Microbiol. Lett. 250, 129-136.
Russo, P., Capozzi, V., Arena, M. P., Spadaccino, G., Dueñas, M. T., López, P., et al. (2014). Riboflavin-overproducing strains of Lactobacillus fermentum for riboflavin-enriched bread. Appl. Microbiol. Biotechnol. 98, 3691-3700. doi: 10.1007/s00253-013-5484-7

Signorini, C., Carpen, A., Coletto, L., Borgonovo, G., Galanti, E., Capraro, J., et al. (2018). Enhanced vitamin B12 production in an innovative lupin tempeh is due to synergic effects of Rhizopus and Propionibacterium in cofermentation. Int. J. Food Sci. Nutr. 69, 451-457. doi: 10.1080/09637486.2017.1386627

Singh, J., Sharma, S., and Nara, S. (2015). Evaluation of gold nanoparticle based lateral flow assays for diagnosis of enterobacteriaceae members in food and water. Food Chem. 170, 470-483. doi: 10.1016/j.foodchem.2014.08.092

Smid, E. J., and Lacroix, C. (2013). Microbe-microbe interactions in mixed culture food fermentations. Curr. Opin. Biotechnol. 24, 148-154. doi: 10.1016/j.copbio. 2012.11.007

Smith, A. D., Warren, M. J., and Refsum, H. (2018). Vitamin B12. Adv. Food Nutr. Res. 83, 215-279. doi: 10.1016/bs.afnr.2017.11.005

Tinzl-Malang, S. K., Rast, P., Grattepanche, F., Sych, J., and Lacroix, C. (2015). Exopolysaccharides from co-cultures of Weissella confusa $11 \mathrm{GU}-1$ and Propionibacterium freudenreichii JS15 act synergistically on wheat dough and bread texture. Int. J. Food Microbiol. 214, 91-101. doi: 10.1016/j.ijfoodmicro. 2015.07.025

Valerio, F., Di Biase, M., Caputo, L., Creanza, T. M., Ancona, N., Visconti, A., et al. (2014). Effect of Lactobacillus brevis-based bioingredient and bran on microbiological, physico-chemical and textural quality of yeast-leavened bread during storage. Innov. Food Sci. Emerg. Technol. 25, 2-8. doi: 10.1016/j.ifset. 2013.09.003

Watanabe, F., Yabuta, Y., Bito, T., and Teng, F. (2014). Vitamin B12-containing plant food sources for vegetarians. Nutrients 6, 1861-1873. doi: 10.3390/ nu6051861

Wolkers-Rooijackers, J. C. M., Endika, M. F., and Smid, E. J. (2018). Enhancing vitamin B 12 in lupin tempeh by in situ fortification. Lwt 96, 513-518. doi: 10.1016/j.lwt.2018.05.062

Xie, C., Coda, R., Chamlagain, B., Edelmann, M., Deptula, P., Varmanen, P., et al. (2018). In situ fortification of vitamin B12 in wheat flour and wheat bran by fermentation with Propionibacterium freudenreichii. J. Cereal Sci. 81, 133-139. doi: 10.1016/j.jcs.2018.05.002

Zsori, K. S., Csiki, Z., Katona, E., Bereczky, Z., and Shemirani, A. H. (2013). Vitamin B12 level in peripheral arterial disease. J. Thromb. Thrombolysis 36, 77-83. doi: 10.1007/s11239-012-0807-6

Conflict of Interest Statement: The authors declare that the research was conducted in the absence of any commercial or financial relationships that could be construed as a potential conflict of interest.

Copyright () 2019 Xie, Coda, Chamlagain, Varmanen, Piironen and Katina. This is an open-access article distributed under the terms of the Creative Commons Attribution License (CC BY). The use, distribution or reproduction in other forums is permitted, provided the original author(s) and the copyright owner(s) are credited and that the original publication in this journal is cited, in accordance with accepted academic practice. No use, distribution or reproduction is permitted which does not comply with these terms. 